\title{
THE IMPLEMENTATION OF ORAL AND DENTAL CARE SERVICES PROGRAM TOWARD DENTAL HEALTH STATUS IN ELEMENTARY SCHOOL 134 / IV JAMBI CITY
}

\section{Junaidi $^{\bowtie 1}$, Pahrur Razi ${ }^{2}$}

\begin{abstract}
ABSTRAK
Program pelayanan asuhan keperawatan gigi dan mulut merupakan salah satu upaya untuk mengatasi masalah kesehatan gigi dan mulut. Politeknik Kesehatan Kemenkes Jambi Jurusan Kesehatan Gigi sebagai institusi pendidikan tinggi, mengemban misi Tridarma Perguruan Tinggi yaitu pengajaran, penelitian dan pengabdian kepada masyarakat. Sebagai salah satu bentuk pengabdian kepada masyarakat yaitu dengan melaksanakan program terintegrasi berupa program pelayanan asuhan keperawatan gigi dan mulut pada murid SD 134/IV Kota Jambi. Tujuan penelitian ini adalah untuk mengetahui status kesehatan gigi dan mulut pada murid SD yang mendapatkan dan tidak mendapatkan pelayanan asuhan keperawatan gigi dan mulut.

Penelitian ini merupakan penelitian kuantitatif dengan metode pendekatan cross sectional study, dan pengumpulan data dari data primer yang diperoleh dari pemeriksaan kesehatan gigi dan mulut dengan menggunakan alat diagnosa set dengan format pemeriksaan gigi. Sampel penelitian sebanyak 30 anak SDN 134/IV Kota Jambi yang pernah mendapatkan pelayanan asuhan keperawatan gigi dan mulut dan 30 anak SD 206/IV Kota Jambi yang tidak mendapat pelayanan asuhan keperawatan gigi dan mulut dengan teknik pengambilan sampel yakni stratified random sampling.

Hasil penelitian rata-rata indeks DMF-T SD yang tidak mendapatkan pelayanan asuhan keperawatan gigi yaitu 2. Sedangkan rata-rata indeks DMF-T yang mendapatkan pelayanan asuhan keperawatan gigi yaitu yaitu 1. Rata-rata indeks OHI-S SD yang tidak mendapatkan pelayanan asuhan keperawatan gigi yaitu 1,6. Sedangkan rata-rata indeks OHI-S yang mendapatkan pelayanan asuhan keperawatan gigi yaitu yaitu 1,2. Hasil uji statistik ada perbedaan indeks DMF-T dan OHI-S pada murid SD yang mendapatkan dengan yang tidak mendapatkan pelayanan asuhan keperawatan gigi dan mulut $(p<0,05)$. Disarankan untuk meningkatkan upaya promotif dan preventif pada SD yang tidak mendapatkan pelayanan asuhan keperawatan gigi dan mulut.
\end{abstract}

Kata kunci : Asuhan keperawatan gigi dan mulut

\begin{abstract}
Oral and dental care services program is one effort to overcome the problem of oral health. Health Polytechnic Kemenkes Jambi Dental Health Department as an institution of higher education, carrying out the mission of Tridarma Perguruan Tinggi is teaching, research, and dedication to society. As one form of community service that is by implementing an integrated program in the form of dental and oral care programs at elementary school students 134 / IV Jambi City. The purpose of this study was to determine the status of oral and dental health in elementary school students who get and do not get care services of dental and oral care.

This research is a quantitative research with cross-sectional study approach, and data collecting from primary data obtained from dental and mouth examination by using a diagnostic set instrument with dental examination format. Samples of research were 30 children of SDN 134 / IV of Jambi who had received dental and oral care services and 30 children of SD 206 / IV of Jambi who was not receiving dental and oral care services with stratified random sampling technique.

Results of the average DMF-T SD index that did not get dental care services of teeth is 2 . While the average index of DMF-T who get services of nursing care of teeth that is 1. Average OHI-S SD index who do not get service dental nursing care is 1.6. While the average index of OHI-S who get services of nursing care of teeth that is 1.2. The result of a statistical test is the difference of DMF-T and OHI-S index in elementary school students who get with those who do not get dental and mouth nursing care ( $p<0,05)$. It is advisable to increase efforts to promote and preventive in primary schools that do not get dental and oral care services.
\end{abstract}

Keywords : Oral and Dental care service

\footnotetext{
${ }^{1,2)}$ Dosen Jurusan Keperawatan Gigi Poltekkes Kemenkes Jambi

凶: joen_jambi@yahoo.com
} 


\section{PENDAHULUAN}

Berdasarkan Undang-Undang No.36 Tahun 2009 tentang kesehatan, pelayanan kesehatan gigi dan mulut dilakukan untuk memelihara dan meningkatkan derajat kesehatan masyarakat dalam bentuk peningkatan kesehatan gigi, pencegahan penyakit gigi, pengobatan penyakit gigi, dan pemulihan kesehatan gigi yang dilakukan terpadu, terintegrasi, berkesinambungan, dan dilaksanakan melalui pelayanan kesehatan gigi perseorangan, pelayanan kesehatan gigi masyarakat, dan usaha kesehatan gigi sekolah.

Kesehatan gigi dan mulut merupakan bagian integral dari pelayanan kesehatan secara keseluruhan. Kesehatan gigi juga merupakan salah satu komponen kesehatan secara menyeluruh dan tidak dapat diabaikan terutama pada tingkat Sekolah Dasar (SD), karena kesehatan gigi dan mulut ikut mempengaruhi tumbuh kembang anak yang sempurna (Depkes, 2004).

Karies gigi merupakan penyakit yang paling banyak dijumpai di rongga mulut bersama-sama dengan penyakit periodontal, sehingga merupakan masalah utama kesehatan gigi dan mulut. Penyakit ini terjadi karena demineralisasi jaringan permukaan gigi oleh asam organis yang berasal dari makanan yang mengandung gula. Karies gigi bersifat kronis sebagian besar penderita mempunyai potensi mengalami gangguan seumur hidup (Tampubolon, 2005).

Menurut Tampubolon

(2005) menunjukkan karies gigi mempunyai dampak yang luas, yaitu gangguan pada kualitas hidup antara lain keterbatasan fungsi gigi (sulit mengunyah, makanan sangkut, nafas bau, pencernaan terganggu), disabilitas fisik (diet tidak memuaskan, menghindari makanan tertentu, tidak bisa menyikat gigi dengan baik), keluhan rasa sakit setiap mengunyah makanan, ngilu, sakit kepala, sakit di rahang), ketidaknyamanan psikis (merasa rendah diri, sangat menderita, kuatir), dan disabilitas psikis (tidur terganggu, sulit berkonsentrasi, merasa malu).

Menurut Sriyono (2005), menyatakan anak-anak yang mempunyai kesehatan gigi dan mulut yang buruk, dua belas kali lebih banyak menderita gangguan aktivitas termasuk tidak masuk sekolah dibanding dengan mereka yang mempunyai kesehatan mulut yang baik. Lebih dari 50 juta jam sekolah pertahun hilang karena penyakit gigi dan mulut yang akan berdampak pada penampilan anak-anak di sekolah dan kesuksesan hidupnya kelak.

Anak usia SD merupakan kelompok anak yang termasuk rentan terhadap karies gigi karena masa pertumbuhan gigi tetap yakni umur 6-12 tahun, disamping itu karies gigi pada murid SD juga dalam kategori dangkal yang masih bisa dilakukan perawatan penambalan dan pencegahan agar tidak terjadi akibat karies gigi lebih lanjut. Kelompok usia 12 tahun merupakan indikator kritis, biasanya berada di kelas VI SD. Usia tersebut karies gigi akan lebih cepat terjadi karena gigi geraham/molar merupakan gigi dimana makanan mudah melekat karena bentuk anatomi fit dan fissure yang dalam, sekitar 76,9\% menyerang pada usia tersebut (Sriyono, 2005).

Sampai saat ini, karies gigi masih merupakan masalah kesehatan baik di negara maju maupun di negara berkembang. Data dari WHO (2000) menunjukkan bahwa ratarata pengalaman karies usia 12 tahun berkisar 2,4. Indeks karies gigi target WHO adalah 1,0 gigi, artinya minimal dalam mulut seseorang minimal satu gigi yang mengalami kerusakan karena karies gigi.

Diperkirakan $90 \%$ dari anak-anak sekolah di seluruh dunia dan sebagian besar orang dewasa pernah menderita karies. Prevalensi tertinggi terdapat di Asia dan Amerika Latin, terendah di Afrika. Di Amerika Serikat, karies merupakan penyakit kronis anak-anak yang sering terjadi dan tingkatnya 5 kali lebih tinggi dari asma (Wikipedia, 2009). 
Berdasarkan Riskesdas 2007, menunjukkan bahwa secara nasional prevalensi karies aktif sebesar 46,5\%, dengan prevalensi tertinggi (lebih dari 50\%) ditemukan di Jambi $(56,1 \%)$. Sedangkan Hasil Riskesdas, 2013, menunjukkan indeks karies gigi di Indonesia sebesar 4,6 dan 5,5 terjadi di Propinsi Jambi.

Berdasarkan Penelitian Rudi., dkk (2010), diperoleh hasil prevalensi karies murid kelas VI SD di daerah urban Kota Jambi adalah 76,02\% dan daerah rural Kota Jambi adalah $68,77 \%$. Sedangkan penelitian Rosmawati., dkk. (2013), menunjukkan bahwa karies gigi pada siswa SD di Kota Jambi sebesar $60,6 \%$ dengan indeks karies sebesar 5,2. Berarti lebih tinggi dari rata-rata nasional atau jauh dari target WHO sebesar 1,0 .

Program pelayanan asuhan keperawatan gigi dan mulut merupakan salah satu upaya untuk mengatasi masalah kesehatan gigi dan mulut. Politeknik Kesehatan Kemenkes Jambi Jurusan Kesehatan Gigi sebagai institusi pendidikan tinggi, mengemban misi Tridarma Perguruan Tinggi yaitu pengajaran, penelitian dan pengabdian kepada masyarakat. Sebagai salah satu bentuk pengabdian kepada masyarakat yaitu dengan melaksanakan program terintegrasi berupa program pelayanan asuhan keperawatan gigi dan mulut.

Menurut Permenkes no. 58 tahun 2012 bahwa tujuan pelayanan asuhan keperawatan gigi dan mulut adalah untuk meningkatkan kemampuan pelihara diri di bidang kesehatan gigi dan mulut, serta status kesehatan gigi dan mulut yang optimal. Sasaran pelayanan asuhan kesehatan gigi dan mulut diutamakan kepada siswa sekolah dasar yang rentan terhadap penyakit gigi dan mulut.

Berdasarkan hasil penelitian Elvira (2010) diketahui SD yang mendapat pelayanan asuhan kesehatan gigi dan mulut yang dilaksanakan oleh mahasiswa Jurusan Keperawatan Gigi Poltekkes Kemenkes Jambi berpengaruh positif yang signifikan terhadap peningkatan pengetahuan, sikap, status kebersihan mulut dan status karies gigi pada murid SD Attaufiq, SD Sari Putra dan SDN 74 Kota Jambi.

Sekolah Dasar Negeri (SDN) 134/IV Kota Jambi adalah Sekolah Dasar yang telah dilaksanakan Program pelayanan asuhan keperawatan gigi dan mulut oleh Jurusan Keperawatan Gigi yang dilaksanakan setiap hari Senin sampai dengan Jum'at, dimana pelayanan diberikan oleh 2 orang operator lulusan DIII-Keperawatan Gigi dengan cakupan pelayanan asuhan mencakup promotif dan preventif. Upaya promotif yang dilakukan yakni penyuluhan tentang kesehatan gigi dan mulut dengan upaya preventif yang dilakukan yakni sikat gigi dan pembersihan karang gigi. Program tersebut telah berjalan 2 tahun, namun kegiatan ini belum pernah dilakukan penelitian untuk melihat perbedaan status kesehatan gigi dan mulut dengan SD yang tidak mendapatkan pelayanan asuhan keperawatan gigi dan mulut yakni SDN 206/IV Kota Jambi.

Tujuan penelitian ingin mengetahui status kesehatan gigi dan mulut pada murid SD yang mendapat pelayanan dan tidak mendapatkan pelayanan asuhan keperawatan gigi dan mulut.

\section{METODE PENELITIAN}

Jenis penelitian adalah survey deskriptif. Sampel dipilih secara Purposive Sampling yaitu anak SD 134/IV dan SD 206/IV Kota Jambi yang berusia $\geq 10$ tahun dan bersedia menjadi responden.

Cara pengumpulan data responden pemeriksaan karies gigi dan kebersihan gigi dan mulut yang dicatat pada formulir pemeriksaan. Data yang sudah dikumpulkan diolah melalui tahapan editing, coding, entry data, dan cleaning data.

Penyajian hasil penelitian diuraikan sesuai dengan tujuan penelitian yaitu mengetahui perbedaan status kesehatan gigi dan mulut pada murid SD yang mendapatkan dan tidak mendapatkan pelayanan asuhan 
keperawatan gigi dan mulut. Analisa data menggunakan analisis univariat dan bivariat (uji t-test).

\section{HASIL DAN PEMBAHASAN}

Berikut ini disajikan hasil penelitian dan pembahasan :

\section{Indeks DMF-T}

Tabel 1. Rata-Rata Indeks DMF-T Pada Murid SD Yang Mendapatkan dan Tidak Mendapatkan Pelayanan Asuhan Keperawatan Gigi

\begin{tabular}{lcc}
\hline & Indeks DMF-T & SD \\
\hline $\begin{array}{l}\text { Mendapatkan } \\
\text { pelayanan asuhan }\end{array}$ & 1 & 1,16 \\
keperawatan gigi & & \\
\hline $\begin{array}{l}\text { Tidak mendapatkan } \\
\text { pelayanan asuhan } \\
\text { keperawatan gigi }\end{array}$ & 2 & 2,24 \\
\hline
\end{tabular}

Berdasarkan Tabel 1 menunjukkan rata-rata indeks DMF-T SD yang tidak mendapatkan pelayanan asuhan keperawatan gigi yaitu 2 dengan standar deviasi 2,24. Sedangkan rata-rata indeks DMF-T yang mendapatkan pelayanan asuhan keperawatan gigi yaitu yaitu 1 dengan standar deviasi 1,16 .

Tabel 2. Perbedaan Rata-Rata Indeks DMF-T Pada Murid SD Yang Mendapatkan dan Tidak Mendapatkan Pelayanan Asuhan Keperawatan Gigi

\begin{tabular}{|c|c|c|c|}
\hline Indeks DMF-T & $\mathbf{t}$ & Df & Sig. \\
\hline $\begin{array}{l}\text { Mendapatkan pelayanan } \\
\text { asuhan keperawatan gigi }\end{array}$ & \multirow[b]{2}{*}{2,73} & \multirow[b]{2}{*}{2} & \multirow[b]{2}{*}{$0,011^{*}$} \\
\hline $\begin{array}{l}\text { Tidak mendapatkan } \\
\text { pelayanan asuhan } \\
\text { keperawatan gigi }\end{array}$ & & & \\
\hline
\end{tabular}

Keterangan $*$ ) signifikan pada $<0,05$

Setelah dianalisis rata-rata indeks DMF-T yang tidak mendapatkan pelayanan asuhan keperawatan gigi yaitu 2 dengan standar deviasi 2,24. Sedangkan rata-rata indeks DMF-T yang mendapatkan pelayanan asuhan keperawatan gigi yaitu yaitu 1 dengan standar deviasi 1,16.
Berdasarkan Tabel 2 menunjukkan bahwa murid SD yang mendapatkan pelayanan asuhan keperawatan gigi dan mulut memiliki indeks DMF-T lebih rendah dibandingkan murid SD yang tidak mendapatkan pelayanan asuhan keperawatan gigi dan mulut dengan nilai t hitung sebesar 2,73 dan signifikansi pada 0,011 ( $p<0,05)$. Artinya ada perbedaan indeks DMF-T pada murid SD yang mendapatkan dengan yang tidak mendapatkan pelayanan asuhan keperawatan gigi dan mulut.

Menurut Kidd (1991) menyatakan bahwa karies merupakan suatu penyakit jaringan keras gigi, yaitu email, dentin dan sementum, yang disebabkan oleh aktivitas suatu jasad renik dalam suatu karbohidrat yang dapat diragikan.

Menurut Herijulianti (2001) menyatakan walaupun telah dilakukan upaya pelayanan kesehatan gigi dan mulut angka kesakitan penyakit gigi dan mulut cenderung terus meningkat.

Berdasarkan Survei Kesehatan Rumah Tangga (SKRT) 2001 menunjukkan bahwa Prevalensi karies aktif pada penduduk umur 10 tahun ke atas adalah 52,3\% (yang belum ditangani) dan penduduk yang pernah mengalami karies sebesar $71,20 \%$. Indeks DMF-T mencapai rata-rata 5,26 ini berarti jumlah kerusakan gigi rata-rata perorangan adalah lebih dari 5 gigi. Performance Treatment Index atau motivasi untuk menumpatkan gigi yang karies pada umur 12-18 tahun sangat rendah sekitar 4-5\% sedangkan besarnya kerusakan yang belum ditangani dan memerlukan penumpatan dan atau pencabutan (Required Treatment Index) pada usia ini sebesar 72,4\% - 82,5\% (Depkes, 2007). Hasil Riset Kesehatan Dasar (RISKESDAS) Propinsi Jambi tahun 2007 menunjukkan bahwa prevalensi karies aktif umur 12 tahun ke atas sebesar 77,9\% (Depkes, 2008).

Menurut peneliti indeks karies gigi kurang baik disebabkan oleh adanya pengaruh jenis makanan kariogenik atau makanan yang lebih cepat menyebabkan karies gigi dan tidak teraturnya 
membersihkan gigi dan mulut sesuai dengan anjuran. Usaha-usaha untuk mencegah terjadinya penyakit gigi dapat dilakukan dengan cara memelihara kebersihan mulut (menghilangkan plak dan bakteri), memperkuat gigi (dengan fluor), mengurangi konsumsi makanan yang manis dan lengket, membiasakan konsumsi makanan berserat dan menyehatkan gigi dan menyikat gigi dengan pasta gigi yang mengandung fluor, melalui pelaksanaan program Usaha Kesehatan Gigi Sekolah (UKGS) yang meliputi upaya promotif dan upaya preventif.

\section{Indeks OHI-S}

Tabel 3. Rata-Rata Indeks OHI-S Pada Murid SD Yang Mendapatkan dan Tidak Mendapatkan Pelayanan Asuhan Keperawatan Gigi

\begin{tabular}{lcc}
\hline \multicolumn{1}{c}{ Indeks OHI-S } & Rata-rata & SD \\
\hline $\begin{array}{l}\text { Mendapatkan } \\
\text { pelayanan asuhan } \\
\text { keperawatan gigi }\end{array}$ & 1,2 & 0,37 \\
\hline $\begin{array}{l}\text { Tidak mendapatkan } \\
\text { pelayanan asuhan } \\
\text { keperawatan gigi }\end{array}$ & 1,6 & 0,78 \\
\hline
\end{tabular}

Berdasarkan Tabel 3 menunjukkan rata-rata indeks OHI-S SD yang tidak mendapatkan pelayanan asuhan keperawatan gigi yaitu 1,6 dengan standar deviasi 0,78. Sedangkan rata-rata indeks OHI-S yang mendapatkan pelayanan asuhan keperawatan gigi yaitu yaitu 1,2 dengan standar deviasi 0,37 .

Tabel 4. Perbedaan Rata-Rata Indeks OHI-S Pada Murid SD Yang Mendapatkan dan Tidak Mendapatkan Pelayanan Asuhan Keperawatan Gigi

\begin{tabular}{llll}
\hline \multicolumn{1}{c}{ Indeks OHI-S } & t & Df & Sig. \\
\hline $\begin{array}{l}\text { Mendapatkan } \\
\text { pelayanan asuhan } \\
\text { keperawatan gigi }\end{array}$ & & & \\
$\begin{array}{l}\text { Tidak mendapatkan } \\
\text { pelayanan asuhan }\end{array}$ & & 29 & $0,008^{*}$ \\
keperawatan gigi & & & \\
\hline
\end{tabular}

Keterangan *) signifikan pada $<0,05$
Berdasarkan Tabel 4 menunjukkan bahwa murid SD yang mendapatkan pelayanan asuhan keperawatan gigi dan mulut memiliki indeks OHI-S lebih rendah dibandingkan murid SD yang tidak mendapatkan pelayanan asuhan keperawatan gigi dan mulut dengan nilai t hitung sebesar 2,857 dan signifikansi pada 0,008 $(\mathrm{p}<0,05)$. Artinya ada perbedaan indeks DMF-T pada murid SD yang mendapatkan dengan yang tidak mendapatkan pelayanan asuhan keperawatan gigi dan mulut.

Setelah dianalisis rata-rata indeks OHI-S SD yang tidak mendapatkan pelayanan asuhan keperawatan gigi yaitu 1,6 dengan standar deviasi 0,78 . Sedangkan ratarata indeks OHI-S yang mendapatkan pelayanan asuhan keperawatan gigi yaitu yaitu 1,2 dengan standar deviasi 0,37.

Menurut Suwelo (1992) Faktor di dalam mulut (faktor dalam) yang berhubungan langsung dengan proses terjadinya karies gigi antara lain struktur gigi, morfologi gigi, susunan gigi geligi di rahang, derajat keasaman $(\mathrm{pH})$ saliva, kebersihan mulut, jumlah dan frekuensi makan makanan kariogenik.

Menurut Peneliti keadaan dan kebersihan mulut perorangan tergantung dari bagaimana seseorang tersebut rutin melakukan menyikat gigi dengan baik dan benar sebanyak 2 kali sehari. Waktu menyikat gigi yang baik adalah sesudah sarapan pagi dan sebelum tidur malam. Oleh karena itu murid SD perlu diberikan penyuluhan cara menyikat gigi yang baik dan benar terutama pada anak SD yang tidak mendapatkan pelayanan asuhan keperawatan gigi dan mulut.

Selanjutnya dari hasil analisis ada perbedaan indeks DMF-T dan OHI-S pada murid SD yang mendapatkan dengan yang tidak mendapatkan pelayanan asuhan keperawatan gigi dan mulut. Menurut Depkes (2004) penyakit gigi yang banyak diderita masyarakat yaitu karies dan penyakit periodontal sebenarnya mudah dicegah yaitu dengan menanamkan kebiasaan/perilaku pemeliharaan kesehatan gigi. 
Menurut peneliti, keadaan ini disebabkan adanya responden yang belum mendapatkan pelayanan asuhan keperawatan gigi dan mulut sehingga tidak menjaga kesehatan gigi dan mulut terutama dalam hal menjaga kebersihan gigi dan mulut. Upaya yang sebaiknya dilakukan adalah mendemonstrasikan cara menyikat gigi yang baik dan benar, meliputi bentuk sikat gigi yang baik, waktu menyikat gigi yang tepat, gerakan menyikat gigi yang benar, serta anjuran untuk selalu mengkonsumsi buahbuahan setiap hari dan memeriksakan kesehatan gigi dan mulut secara rutin 6 bulan sekali ke puskesmas/poli gigi.

Peran petugas kesehatan gigi agar menganjurkan murid SD untuk menyikat gigi yakni pagi sesudah sarapan dan malam sebelum tidur. Sehingga perlu kerjasama petugas kesehatan gigi untuk meningkatkan derajat kesehatan gigi dan mulut agar terhindar terjadinya penyakit gigi dan mulut. Sebaiknya Pihak SDN 206/IV Kota Jambi bekerjasama Puskesmas dan Jurusan Keperawatan Gigi dalam program pelayanan asuhan keperawatan gigi dan mulut murid SD.

\section{KESIMPULAN}

Berdasarkan penelitian ini dapat disimpulkan :

1. Rata-rata indeks DMF-T SD yang tidak mendapatkan pelayanan asuhan keperawatan gigi yaitu 2. Sedangkan ratarata indeks DMF-T yang mendapatkan pelayanan asuhan keperawatan gigi yaitu yaitu 1. Rata-rata indeks OHI-S SD yang tidak mendapatkan pelayanan asuhan keperawatan gigi yaitu 1,6. Sedangkan rata-rata indeks OHI-S yang mendapatkan pelayanan asuhan keperawatan gigi yaitu yaitu 1,2.

2. Ada perbedaan indeks DMF-T pada murid SD yang mendapatkan dengan yang tidak mendapatkan pelayanan asuhan keperawatan gigi dan mulut, dimana murid SD yang mendapatkan pelayanan asuhan keperawatan gigi dan mulut memiliki indeks DMF-T lebih rendah dibandingkan murid SD yang tidak mendapatkan pelayanan asuhan keperawatan gigi dan mulut dengan nilai $t$ hitung sebesar 2,732 dan signifikansi pada $0,011(\mathrm{p}<0,05)$.

3. Ada perbedaan indeks OHI-S pada murid SD yang mendapatkan dengan yang tidak mendapatkan pelayanan asuhan keperawatan gigi dan mulut, dimana murid SD yang mendapatkan pelayanan asuhan keperawatan gigi dan mulut memiliki indeks OHI-S lebih rendah dibandingkan murid SD yang tidak mendapatkan pelayanan asuhan keperawatan gigi dan mulut dengan nilai $t$ hitung sebesar 2,857 dan signifikansi pada $0,008(\mathrm{p}<0,05)$.

\section{SARAN}

Berdasarkan hasil penelitian, diharapkan untuk penelitian selanjutnya lebih difokuskan pada sampel yang lebih besar.

\section{DAFTAR PUSTAKA}

Budiarto, 2005, Metode Penelitian Kedokteran, hal. 46-47, EGC, Jakarta.

Budiharto, 2008, Metode Penelitian Kesehatan, EGC, Penerbit Buku Kedokteran, Jakarta.

Depkes., 1995, Tata Cara Kerja Pelayanan Asuhan Kesehatan Gigi Dan Mulut Di Puskesmas, Jakarta.

Elvira, 2010. Perbandingan pengetahuan, sikap, dan status kesehatan gigi dan mulut pada murid SD yang mendapatkan dan tidak mendapatkan pelayanan asuhan kesehatan gigi dan mulut. Studi pada SD Attufiq, SD Sari Putra dan SDN 74/IV Kota Jambi. Thesis. UGM Yokyakarta.

Kemenkes RI, 2010, Media Penelitian Dan Pengembangan Kesehatan, Jakarta. 
Kidd, E. A.M. Bechal, Joyston, S., 1991, DasarDasar Karies Penyakit Dan Penanggulangannya, EGC, Jakarta.

Kidd, dkk., 2002, Manual Konservasi Restorative Edisi-6. Hal. 3. Widya medika, Jakarta.

Machfoedz, I. dan Zein, A. Y, 2005. Menjaga Kesehatan Gigi Dan Mulut Anak-Anak Dan Ibu Hamil, Fitramaya, Yogyakarta.

Mangoenprasodjo, S., 2004, Gigi Sehat Mulut Terjaga, Think Fresh, Yogyakarta.

Pickard, H. M., Smith. B.G.N. 2000. Manual Konservasi Restorative, hal. 3, widya medika, Jakarta.

Riskesdas, 2013, Riset Kesehatan Dasar, Kementerian Kesehatan RI. Jakarta.

Sriyono, W, N., 2005, Pengantar Ilmu Kedokteran Gigi Pencegahan, Medika Fakultas Kedokteran Gigi, UGM, Yogyakarta.

Suwelo, I.S. 1992, Karies Pada Anak Dengan Berbagai Faktor Etiologi, hal. 1,4,6,8,31. EGC, Jakarta. 